\title{
Copper(I) Thiocyanate Networks with Aliphatic Sulfide Ligands.
}

\author{
Gerardo Ayala and Robert D. Pike* \\ Department of Chemistry, College of William and Mary, Williamsburg, VA 23187.
}

\begin{abstract}
A total of five new CuSCN-L compounds with alkyl sulfide ligands, $\mathrm{L}=$ methyl sulfide $\left(\mathrm{Me}_{2} \mathrm{~S}\right)$, ethyl sulfide $\left(\mathrm{Et}_{2} \mathrm{~S}\right)$, isopropyl sulfide $\left(\operatorname{Pr}_{2}^{i} \mathrm{~S}\right)$ or tetrahydrothiophene (THT) have been prepared and characterized. X-ray crystal structures for four of the compounds were obtained. Two compounds were collected from solutions of $\mathrm{CuSCN}$ in $\mathrm{Me}_{2} \mathrm{~S}:\left\{\left[\mathrm{Cu}(\mathrm{SCN})\left(\mathrm{Me}_{2} \mathrm{~S}\right)_{2}\right]\right\}_{\mathrm{n}}(\mathbf{1 a})$ in the form of colorless blocks and $(\mathrm{CuSCN})\left(\mathrm{Me}_{2} \mathrm{~S}\right)(\mathbf{1 b})$ as a white powder. Neat mixtures of $\mathrm{CuSCN}$ in the other alkyl sulfide ligands yielded only one product each: $\left\{\left[\mathrm{Cu}(\mathrm{SCN})\left(\mathrm{Et}_{2} \mathrm{~S}\right)\right]\right\}_{\mathrm{n}} \quad(\mathbf{2}) ; \quad\left\{\left[\mathrm{Cu}(\mathrm{SCN})\left(\operatorname{Pr}_{2}^{i} \mathrm{~S}\right)\right]\right\}_{\mathrm{n}} \quad(3)$; and $\left\{\left[\mathrm{Cu}(\mathrm{SCN})(\mathrm{THT})_{2}\right]\right\}_{\mathrm{n}}(\mathbf{4})$. Crystals of $\mathbf{2}$ and $\mathbf{4}$ underwent destructive phase changes at lower temperatures. Two networks types were observed: 1:2 decorated 1-D chains (1a and $\mathbf{4})$ and 1:2 decorated 1-D ladders (2 and 3). Further network formation through bridging of the organic sulfide ligands was not observed.
\end{abstract}

Keywords: Copper thiocyanate complexes; Crystal structures; Sulfide ligands; Network structures; Thermogravimetry 


\section{Introduction}

Organosulfur ligands occupy an important niche in transition metal chemistry. As soft ligands, they are able to stabilize soft metal ions in low oxidation states. By virtue of their vacant d-orbitals and ancillary lone pairs, such ligands can potentially act either as $\pi$-donors or $\pi$-acceptors, depending upon their substituent electron demand. Sulfur ligands readily bridge metal centers, facilitating the formation of oligomers and polymers. Nevertheless, they also tend to solubilize metal salts, in particular $\mathrm{Cu}(\mathrm{I})$ salts. Thus, $\mathrm{CuX} \cdot \mathrm{Me}_{2} \mathrm{~S}(\mathrm{X}=\mathrm{Cl}, \mathrm{Br}, \mathrm{I}$, and $\mathrm{CN})$ is a convenient carrier of copper(I) salts in organic reactions [1]. There are many known complexes of $\mathrm{CuX}$ with sulfur ligands, including sulfides [2], thiolates [3], thioamides [4], and phosphine sulfides [5]. Their structural types include polymers and networks based on $\mathrm{Cu}_{2} \mathrm{X}_{2}$ dimers, $\mathrm{Cu}_{2} \mathrm{X}_{2}$ ladders, and $(\mathrm{CuX})_{\infty}$ polymers and oligomers. In some cases, such as that of $\mathrm{CuI}$ with tetrahydrothiophene (THT), many stoichiometries can be realized from the same combination of components [2f].

In the preceding paper, we described new networks of copper(I) thiocyanate coordinated with aromatic diimine ligands [6]. These fall into categories including 4-coordinate $\mathrm{Cu}$ and 3-coordinate $\mathrm{Cu}$ $(\mathrm{CuSCN})_{\infty}$ chains, $\left[\mathrm{Cu}_{2} \mathrm{~S}(\mathrm{SCN})_{2}\right]_{\infty}$ ladders, and $(\mathrm{CuSCN})_{\infty}$ sheets. Surprisingly, there have as yet been no reports of simple alkyl sulfide complexes of CuSCN. The only related structure we uncovered was that of $(\mathrm{CuSCN})_{2}\left(1,10\right.$-dithia-18-crown-6) [7]. In this complex the bis-sulfide ligand bridges $\left[\mathrm{Cu}_{2}(\mathrm{SCN})_{2}\right]_{\infty}$ ladders, forming a sheet network. Only the sulfur atoms in the crown ether/thioether molecule coordinate to $\mathrm{Cu}(\mathrm{I})$; the harder oxygen atoms fail to interact with the soft $\mathrm{Cu}(\mathrm{I})$. Herein we present the synthesis of five new CuSCN-L compounds, containing the aliphatic sulfides $\mathrm{L}=\mathrm{Me}_{2} \mathrm{~S}, \mathrm{Et}_{2} \mathrm{~S}, \mathrm{Pr}_{2}^{\mathrm{i}} \mathrm{S}$, and THT. Four new crystal structures, falling in CuSCN chain and ladder categories, were solved and are discussed.

\section{Experimental}

2.1 Materials and Methods. All reagents were purchased from Aldrich or Acros and used without purification. Commercial CuSCN (Aldrich) was shown by FTIR to consist solely of the $\alpha$-phase [8]. IR 
spectra were collected on a Shimadzu IRTracer-100 instrument using a diamond ATR probe (spectra shown in Supporting Information). Analyses for $\mathrm{C}, \mathrm{H}$, and $\mathrm{N}$ proved impossible for the compounds described herein due to high ligand lability. Atomic absorption (AAS) analyses for $\mathrm{Cu}$ were carried out using a Perkin-Elmer AAnalyst 700 as previously described [9]. Thermogravimetric analyses (TGA) were conducted using a TA Instruments Q500 in the dynamic (variable temp.) mode with a maximum heating rate of $50{ }^{\circ} \mathrm{C} / \mathrm{min}$. to $800{ }^{\circ} \mathrm{C}$ under $50 \mathrm{~mL} / \mathrm{min}$. $\mathrm{N}_{2}$ flow.

\subsection{Syntheses}

$\left\{\left[\mathrm{Cu}(\mathrm{SCN})\left(\mathrm{Me}_{2} \mathrm{~S}_{2}\right]\right\}_{n}\right.$, 1a. CuSCN $(131 \mathrm{mg}, 1.07 \mathrm{mmol})$ was dissolved in $480 \mu \mathrm{L}$ of neat $\mathrm{Me}_{2} \mathrm{~S}$ in a vial. The resulting brown solution was placed in a freezer for $3 \mathrm{~d}$. The colorless crystals that formed were collected by siphoning excess ligand from the vial. The crystals were washed with pentane and airdried for no more than 5 min. Yield: $82 \mathrm{mg}, 38.9 \%$. Samples were immediately analyzed via TGA, IR, and AAS. IR ( $\mathrm{cm}^{-1}$ ): 2920 (weak), 2098 (v strong), 1419, 1029, 979, 771, 682. Anal. Calcd for $\mathrm{C}_{5} \mathrm{H}_{12} \mathrm{NCuS}_{3}: \mathrm{Cu}, 25.8$. Found: $\mathrm{Cu}, 25.2$. Due to sample instability, $\mathrm{CHN}$ analysis was not possible. TGA calcd for $(\mathrm{CuSCN})\left(\mathrm{Me}_{2} \mathrm{~S}\right): 74.7 \%$. Found: $70.22 \%\left(20-50{ }^{\circ} \mathrm{C}\right)$. Calcd for $\mathrm{CuSCN}: 49.4 \%$. Found: $53.6 \%$ $\left(50-130{ }^{\circ} \mathrm{C}\right)$.

$\left\{\left[(\mathrm{CuSCN})\left(\mathrm{Me}_{2} \mathrm{~S}\right)\right]\right\}_{n}, \mathbf{1 b}$. CuSCN $(271 \mathrm{mg}, 2.23 \mathrm{mmol})$ was dissolved in $1.5 \mathrm{~mL}$ of neat $\mathrm{Me}_{2} \mathrm{~S}$. The resulting suspension was stirred at room temperature for $1 \mathrm{~h}$ in a sealed vial, with the solid dissolving completely into the ligand after only a few minutes. The product was precipitated with addition of pentane. The resulting white solid was collected via filtration, and washed with pentane. Because of the ready loss of sulfide, the product was dried for no more than $5 \mathrm{~min}$. prior to storage in a freezer $(271 \mathrm{mg}$, $51.3 \%$ yield). Samples were immediately analyzed via TGA, IR, and AAS. IR ( $\left.\mathrm{cm}^{-1}\right): 2117$ (v strong), 1415, 1037, 975, 759. Anal. Calcd for $\mathrm{C}_{3} \mathrm{H}_{6} \mathrm{NCuS}_{2}$ : $\mathrm{Cu}, 34.6$. Found: $\mathrm{Cu}, 35.1$. Due to sample instability, $\mathrm{CHN}$ analysis was not possible. TGA calculated for $\mathrm{CuSCN}: 66.1 \%$. Found: $67.1 \%\left(35-120^{\circ} \mathrm{C}\right)$.

$\left\{\left[C u(S C N)\left(E t_{2} S\right)\right]\right\}_{n}, 2$. CuSCN (96 mg, $\left.0.798 \mathrm{mmol}\right)$ was dissolved in $2 \mathrm{~mL}$ of neat $\mathrm{Et}_{2} \mathrm{~S}$ in a vial. The solid dissolved within 20 min. with stirring. The solution was stirred for $3 \mathrm{~d}$. Precipitation with 
ethyl ether resulted in a white powder, which was isolated by filtration and washed with ether. The product was dried for no more than $5 \mathrm{~min}$. due to ready loss of ligand (103 $\mathrm{mg}, 61.6 \%$ ). Due to sample instability, CHN analysis was not possible. IR ( $\mathrm{cm}^{-1}$ ): 2970 (weak), 2169 (v strong), 1446, 1377, 1259, 974, 746. Anal. Calcd for $\mathrm{C}_{5} \mathrm{H}_{10} \mathrm{CuNS}_{2}$ : $\mathrm{Cu}, 30.0$. Found: $\mathrm{Cu}, 32.5$. TGA calculated for $\mathrm{CuSCN}$ : $58.4 \%$. Found: $61.6 \%\left(45-95{ }^{\circ} \mathrm{C}\right)$.

$\left\{\left[\mathrm{Cu}(\mathrm{SCN})\left(\operatorname{Pr}_{2}^{i} \mathrm{~S}\right)\right]\right\}_{n}, 3$. The procedure for 2 was followed, using $85 \mathrm{mg}(0.699 \mathrm{mmol}) \mathrm{CuSCN}$ and $2 \mathrm{~mL}$ of neat $\operatorname{Pr}_{2}^{i} \mathrm{~S}$. The solid did not dissolve completely. The suspension was stirred for $3 \mathrm{~d}$. A white powder was collected via filtration and washed with ethyl ether (110 mg, 65.6\%). IR ( $\left.\mathrm{cm}^{-1}\right)$ : 2974 (weak), 2924 (weak), 2866 (weak), 2924 (weak), 2866 (weak), 2110 (strong), 1442, 1381, 1365, 1238, 1153, 1045, 929, 906, 883, 860, 748. Anal. Calcd for $\mathrm{C}_{7} \mathrm{H}_{14} \mathrm{CuNS}_{2}$ : $\mathrm{Cu}, 26.5$. Found: $\mathrm{Cu}, 26.9$. Due to sample instability, $\mathrm{CHN}$ analysis was not possible. TGA calculated for CuSCN: 50.7\%. Found: 54.8\% (40-75 $\left.{ }^{\circ} \mathrm{C}\right)$.

$\left\{\left[\mathrm{Cu}(\mathrm{SCN})(\mathrm{THT})_{2}\right]\right\}_{n}, 4$. The procedure for 2 was followed, using $91 \mathrm{mg}(0.748 \mathrm{mmol}) \mathrm{CuSCN}$ and $2 \mathrm{~mL}$ of neat THT. The solid did not dissolve completely. The suspension was stirred for $3 \mathrm{~d}$. A white powder was collected via filtration and washed with ethyl ether (186 mg, 83.4\%). IR ( $\left.\mathrm{cm}^{-1}\right): 2951,2125$ (strong), 1435, 1253, 883, 756, 671. Anal. Calcd for $\mathrm{C}_{9} \mathrm{H}_{16} \mathrm{CuNS}_{3}$ : $\mathrm{Cu}, 21.3$. Found: $\mathrm{Cu}, 21.6$. Due to sample instability, CHN analysis was not possible. TGA calcd for (CuSCN)(THT): 70.4\%, Found: 72.8 $\left(31-50{ }^{\circ} \mathrm{C}\right)$. Calcd for CuSCN: 40.0\%. Found: $43.3 \%\left(60-95^{\circ} \mathrm{C}\right)$.

\subsection{Crystallizations}

Single crystals were grown using several techniques. Once removed from mother liquor, all crystals were immediately placed into Paratone $\mathrm{N}$ oil and then mounted under a stream of dry air at 100 K. Crystals of 1a were grown as described above, resulting in colorless blocks. For 2, $80 \mathrm{mg}$ of CuSCN were stirred in $2 \mathrm{~mL}$ of $\mathrm{Et}_{2} \mathrm{~S}$ for $1 \mathrm{~h}$. The vial was then left uncapped and undisturbed in a fume hood. Overnight evaporation of excess $\mathrm{Et}_{2} \mathrm{~S}$ left colorless blades of 2. For $\mathbf{3}$ and 4, $119 \mathrm{mg}$ of $\mathrm{CuSCN}$ were stirred with $4 \mathrm{~mL}$ of neat THT, and $117 \mathrm{mg}$ of CuSCN were stirred with $4 \mathrm{~mL}$ of neat $\operatorname{Pr}_{2}^{i} \mathrm{~S}$ in sealed vials 
under $\mathrm{Ar}$ in an oil bath at $70{ }^{\circ} \mathrm{C}$ for $3 \mathrm{~d}$. CuSCN dissolved completely in THT in this procedure. The vial was allowed to cool to room temp before being placed in a freezer. Colorless plates of $\mathbf{4}$ grew over $3 \mathrm{~d}$. Although the $\operatorname{Pr}_{2}^{i} \mathrm{~S}$ compound never fully dissolved in the neat ligand, long colorless needles of $\mathbf{3}$ suitable for diffraction grew as the vial was left to cool at room temp.

\section{$2.4 X$-ray data collection, structure solutions and refinements}

All X-ray measurements were made using graphite-monochromated $\mathrm{Cu} \mathrm{K} \alpha$ radiation on a BrukerAXS three-circle diffractometer, equipped with a SMART Apex II CCD detector. Crystals of 2 and 4 underwent destructive phase changes at reduced temperatures, even as high as $250 \mathrm{~K}$. Data for 2 and 4 were collected at room temperature $(298 \mathrm{~K})$. Data for $1 \mathbf{a}$ and $\mathbf{3}$ were collected at $100 \mathrm{~K}$. Initial space group determination was based on a matrix consisting of 120 frames. The data were corrected for Lorentz and polarization [10] effects and absorption using SADABS [11]. The structures were solved using intrinsic phasing methods. Structure solution, refinement and the calculation of derived results were performed using the SHELXTL [12] package of software and ShelXle [13]. Non-hydrogen atoms were refined anisotropically. Hydrogen atoms were placed in theoretical positions.

Powder diffraction analysis was carried out on the instrument described above. Samples were rapidly ground and prepared as mulls using Paratone N oil. Four 180 s frames were collected, covering $8-$ $100^{\circ} 2 \theta$. Frames were merged using the SMART Apex II software [14] and were further processed using DIFFRAC.EVA software [15].

\section{Results and Discussion}

\subsection{Synthesis and characterization}

Copper(I) thiocyanate complexes with dialkyl sulfide ligands were generated easily via dissolution or suspension of CuSCN in neat sulfide ligand. The off-white CuSCN dissolved completely in $\mathrm{Me}_{2} \mathrm{~S}$ and $\mathrm{Et}_{2} \mathrm{~S}$ after only a few minutes of stirring. A white ligated product was readily precipitated from the neat sulfide solution via addition of pentane or ethyl ether. Although CuSCN was not fully soluble in $\operatorname{Pr}_{2}^{i} \mathrm{~S}$ or THT at room temperature, stirring of the two-phase mixtures over several days enabled complete 
conversion to the white sulfide products. Reaction of CuSCN was found to afford two different products from neat $\mathrm{Me}_{2} \mathrm{~S}$ solution, depending on the conditions of product isolation. Colorless crystals grown by cooling highly concentrated solutions of $\mathrm{CuSCN}$ in $\mathrm{Me}_{2} \mathrm{~S}$ were found to be have 1:2 stoichiometry: $(\mathrm{CuSCN})\left(\mathrm{Me}_{2} \mathrm{~S}\right)_{2}$, 1a. This result was confirmed via both X-ray diffraction and TGA. A white powder obtained by pentane precipitation of the solid from the $\mathrm{CuSCN} / \mathrm{Me}_{2} \mathrm{~S}$ solution analyzed as a $1: 1$ compound: $(\mathrm{CuSCN})\left(\mathrm{Me}_{2} \mathrm{~S}\right), \mathbf{1 b}$, by thermogravimetric analysis (TGA) and atomic absorption analysis. As shown in Figure 1, the $\mathrm{Me}_{2} \mathrm{~S}$ compounds produced distinct X-ray powder diffraction traces. Each of the other sulfides produced only a single product phase when reacted with $\mathrm{CuSCN}:\left\{\left[\mathrm{Cu}(\mathrm{SCN})\left(\mathrm{Et}_{2} \mathrm{~S}\right)\right]\right\}_{\mathrm{n}}$, 2, $\left\{\left[\mathrm{Cu}(\mathrm{SCN})\left(\operatorname{Pr}_{2}^{i} \mathrm{~S}\right)\right]\right\}_{\mathrm{n}}, \mathbf{3}$, and $\left\{\left[\mathrm{Cu}(\mathrm{SCN})(\mathrm{THT})_{2}\right]\right\}_{\mathrm{n}}, \mathbf{4}$.

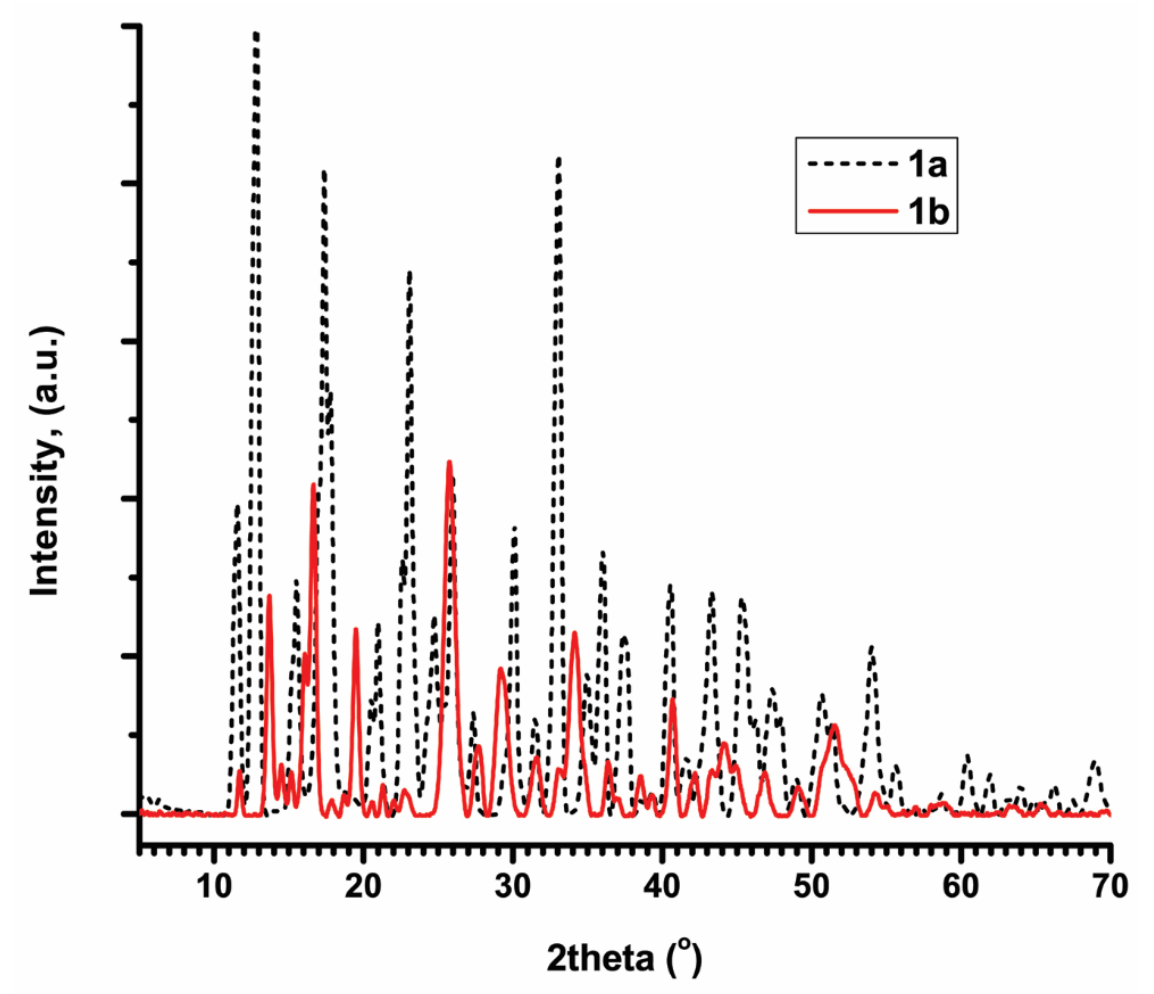

Figure 1. Powder X-ray diffraction comparison of complexes $\mathbf{1 a}$ and $\mathbf{1 b .}$

None of the five compounds prepared herein was thermally stable. Instead, each compound steadily lost ligand at ambient temperature over the course of hours. This was apparent upon examination of TGA data collected on samples after relatively short and longer drying times. Thermal decomposition 


\subsection{Description of X-Ray Structures}

A total of four crystal structures were solved during the course of this study. The resulting structures fall into two recognized categories: 1-D chains and 1-D ladders. All of the alkyl sulfide compounds were found to behave as monodentate capping ligands, precluding the formation of multidimensional networks. This was a surprising finding given the propensity of alkyl sulfide ligands to bridge in complexes of $\mathrm{CuCl}, \mathrm{CuBr}, \mathrm{CuI}$, and $\mathrm{CuCN}$ [2]. Crystallographic data are summarized in Table 1. Selected bond lengths and angles are given in Table S1.

Compound 1a crystallized as colorless blocks that solved in centrosymmetric monoclinic space group $P 2{ }_{1} / c$. A chain diagram is shown in Figure 2. The structure consists of a 1-D CuSCN chain with the four-coordinate $\mathrm{Cu}$ centers capped by pairs of $\mathrm{Me}_{2} \mathrm{~S}$ ligands. The CuSCN chain propagates along the crystallographic $c$-axis. Both $\mathrm{Cu}-\mathrm{S}$ bonds associated with the sulfide molecules $(\mathrm{Cu}-\mathrm{S} 2=2.3456(5), \mathrm{Cu}-$ $\mathrm{S} 3=2.2869(4) \AA)$ are shorter than that of the thiocyanate $(\mathrm{Cu}-\mathrm{S} 1=2.3783(6) \AA)$. The chain has a zigzag angle $\mathrm{N} 1-\mathrm{Cu} 1-\mathrm{S} 1$ of $106.73(5)^{\circ}$. This is the smallest of the roughly tetrahedral angles about $\mathrm{Cu}$, which range from 106.73(5) to $117.24(5)^{\circ}$. The single independent $\mathrm{CuSCN}$ unit lies in two positions that are slightly displaced from one another, such that a $\mathrm{Cu} 1{ }^{\cdots} \mathrm{Cu} 1{ }^{\cdots} \mathrm{Cu} 1$ angle of $173.64^{\circ}$ and a $\mathrm{S} 1{ }^{\cdots} \mathrm{Cu} 1{ }^{\cdots} \mathrm{Cu} 1{ }^{\cdots} \mathrm{S} 1$ dihedral angle of $27.06^{\circ}$ are seen. There are no apparent inter-chain interactions. 


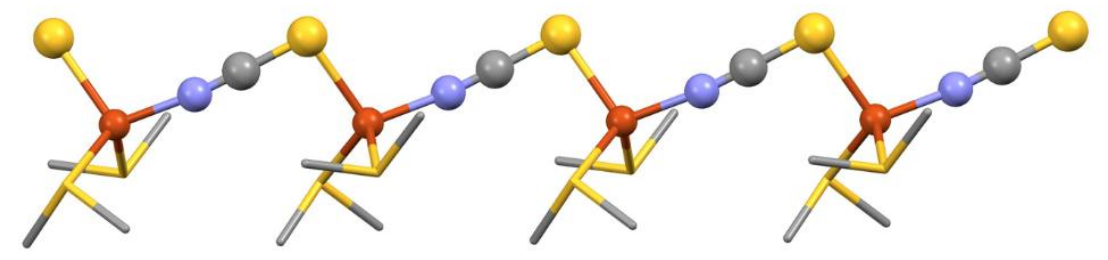

Figure 2: The chain structure of 1a viewed along $b$-axis $\mathrm{CuSCN}$ atoms shown as ball and stick, and $\mathrm{Me}_{2} \mathrm{~S}$ atoms as wireframe. Hydrogen atoms are omitted. Color scheme for all X-ray figures: orange $=\mathrm{Cu}$, yellow $=\mathrm{S}$, grey $=\mathrm{C}$, blue $=\mathrm{N}$. Selected bond lengths $(\AA)$ and angles $\left({ }^{\circ}\right): \mathrm{Cu}-\mathrm{SCN}=2.3784(5), \mathrm{Cu}-\mathrm{NCS}$ $=1.9493(17), \mathrm{Cu}-\mathrm{SR}_{2}=2.2868(5), 2.3456(5), \mathrm{Cu}-\mathrm{S}-\mathrm{C}=96.41(7), \mathrm{C}-\mathrm{N}-\mathrm{Cu}=170.51(16)$.

Compound 2 crystallized as colorless blades that solved in the centrosymmetric monoclinic space group $P 2_{1} / n$. The asymmetric unit consists of $\mathrm{Cu}(\mathrm{SCN})\left(\mathrm{Et}_{2} \mathrm{~S}\right)$. A structure diagram is shown in Figure 3 . Crystals of this compound underwent a destructive phase change upon modest reduction in temperature, necessitating data collection at $298 \mathrm{~K}$. Even the ambient temperature structure retained relatively poor crystallographic ordering. The disordered $\mathrm{Et}_{2} \mathrm{~S}$ ligand was modelled over two positions, and still shows rather larger thermal ellipsoids (see Supporting Information). The network in 2 consists of CuSCN ladders capped by $\mathrm{Et}_{2} \mathrm{~S}$ ligands. The ladders are formed by the crosslinking of antiparallel $\mathrm{CuSCN}$ chains by $\mu_{3}-\mathrm{S}$. The sulfur atoms of the thiocyanate groups bridge between pairs of $\mathrm{Cu}$ atoms, resulting in alternating, edge-sharing $\mathrm{Cu}_{2} \mathrm{~S}_{2}$ and $\mathrm{Cu}_{2}(\mathrm{SCN})_{2}$ dimers. The ladders propagate along the crystallographic $a$-axis. A single diethyl sulfide ligand completes the roughly tetrahedral coordination sphere around copper $\left(\right.$ angles $\left.=103.16(8)-121.80(12)^{\circ}\right)$. In $\mathbf{2}$, the distance between the $\mathrm{Cu}$ atoms across the rhomboid $\mathrm{Cu}_{2} \mathrm{~S}_{2}$ dimer is 2.8893 (7) $\AA$, falling just outside the van der Waals radius sum for copper $(2.8 \AA)$. This short distance results in a relatively small $\mathrm{Cu}-\mathrm{S}-\mathrm{Cu}$ angle of $72.74(3)^{\circ}$. Distances between $\mathrm{Cu}$ and thiocyanate $\mathrm{S}(\mathrm{Cu}-\mathrm{S}=2.368(1), 2.500(1) \AA)$ are slightly longer than those between $\mathrm{Cu}$ and $\mathrm{S}$ of the aliphatic ligand $(\mathrm{Cu}-\mathrm{S} 2 \mathrm{~A}=2.227(5), \mathrm{Cu}-\mathrm{S} 2 \mathrm{~B}=2.294(9) \AA)$. Adjacent ladders are rotated by $90^{\circ}$ with respect to one another, and there are no significant interactions between the ladders. 
Compound $\mathbf{3}$ crystallized as thin colorless needles that solved in the centrosymmetric monoclinic space group $P 2_{1} / n$. The asymmetric unit consists of $\mathrm{Cu}(\mathrm{SCN})\left(\operatorname{Pr}_{2}^{i} \mathrm{~S}\right)$. A structural diagram is shown in Figure 4. This compound displays the same ladder networking as was seen with $\mathbf{2}$. Unlike $\mathbf{2}$, the crystal did not undergo a destructive phase change at reduced temperatures, and the ligand molecules were not disordered. Some important structural differences between $\mathbf{2}$ and $\mathbf{3}$ are apparent when examining the $\mathrm{Cu}_{2} \mathrm{~S}_{2}$ dimers. The ladders in $\mathbf{3}$, which propagate along the $a$-axis are all aligned, unlike those in $\mathbf{2}$. In $\mathbf{3}$, the dimer $\mathrm{Cu}^{\cdots} \mathrm{Cu}=3.1662(5) \AA$, with a corresponding dimer $\mathrm{Cu}-\mathrm{S}-\mathrm{Cu}$ angle of $81.08(2)^{\circ}$. This trend of increasing $\mathrm{Cu}-\mathrm{S}-\mathrm{Cu}$ angle with increasing $\mathrm{Cu}{ }^{*} \mathrm{Cu}$ has been noted in other $\mathrm{CuSCN}$ ladder compounds and in $(\mathrm{CuI})_{2}$ Qox, which contains both long and short $\mathrm{Cu} \cdots \mathrm{Cu}[6,9,16]$. As was the case in $\mathbf{1 a}$ and $\mathbf{2}$, bond distances between the copper and thiocyanate sulfur atoms (2.4816(6) and 2.3883(6) $\AA$ ) are slightly longer than that for the sulfide ligand $(2.2740(5) \AA)$. There are no interactions between adjacent ladders. 


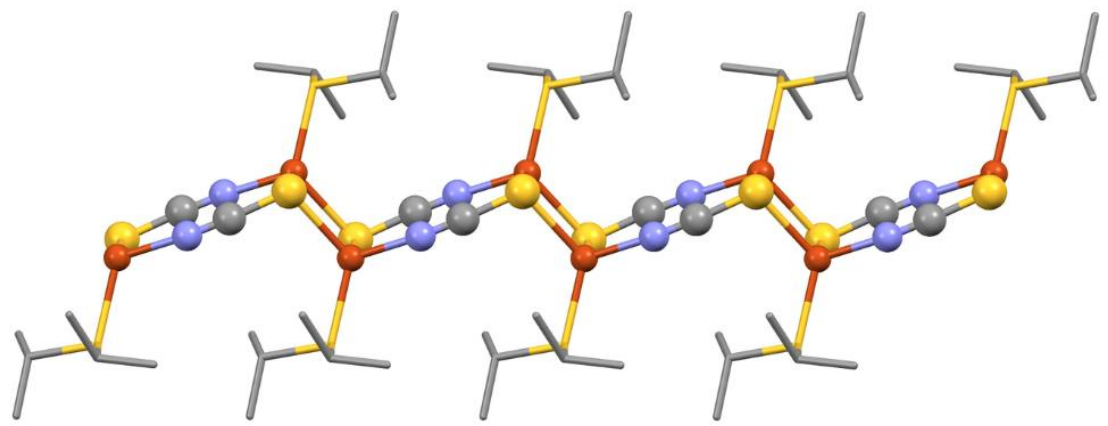

Figure 4: The ladder structure of $\mathbf{3}$ viewed along $c$-axis. CuSCN atoms shown as ball and stick, and $\operatorname{Pr}_{2}^{i} \mathrm{~S}$ atoms as wireframe. Hydrogen atoms are omitted. Selected bond lengths $(\AA)$ and angles $\left({ }^{\circ}\right): \mathrm{Cu}-\mathrm{SCN}=$ 2.3883(5), 2.4816(5), $\mathrm{Cu}-\mathrm{NCS}=1.9629(16), \mathrm{Cu}-\mathrm{SR}_{2}=2.2739(5), \mathrm{Cu}{ }^{\cdots} \mathrm{Cu}=3.1662(6), \mathrm{Cu}-\mathrm{S}-\mathrm{C}=$ 97.08(7), 107.43(7), $\mathrm{C}-\mathrm{N}-\mathrm{Cu}=160.64(15), \mathrm{Cu}-\mathrm{S}-\mathrm{Cu}=81.084(17)$.

Compound 4 crystallized as thin, colorless and transparent plates, solving in the noncentrosymmetric monoclinic space group $P 2{ }_{1}$. As was the case with $\mathbf{2}$, the crystals of $\mathbf{4}$ underwent a destructive phase just below ambient temperature, and so data were collected at $298 \mathrm{~K}$. The complex also showed ligand disorder (see Supporting Information). In this case there are two THT ligands, both of which were modelled over two disordered positions. Like 1a, the structure of $\mathbf{4}$ consists of a 1-D CuSCN chain with four-coordinate $\mathrm{Cu}$ atoms capped by pairs of THT ligands. The $\mathrm{CuSCN}$ chain propagates along the $a$-axis. A chain diagram is shown in Figure 5. The zigzag angle, N1-Cu1-S1, is $110.06(15)^{\circ}$, and all angles around $\mathrm{Cu}$ are fairly close to tetrahedral: $103.5(3)-117.7(6)^{\circ}$. Unlike 1a, the thiocyanate $\mathrm{Cu}-\mathrm{S}$ $(2.344(2) \AA)$, falls within the range of the $\mathrm{Cu}-\mathrm{S}_{\mathrm{THT}}$ distances: $\mathrm{Cu}-\mathrm{S} 2 \mathrm{~A}=2.40(2), \mathrm{Cu}-\mathrm{S} 2 \mathrm{~B}=2.35(2) \mathrm{Cu}-$ $\mathrm{S} 3 \mathrm{~A}=2.19(2), \mathrm{Cu}-\mathrm{S} 3 \mathrm{~B}=2.366(6) \AA$. Once again, no significant interactions between chains are noted.

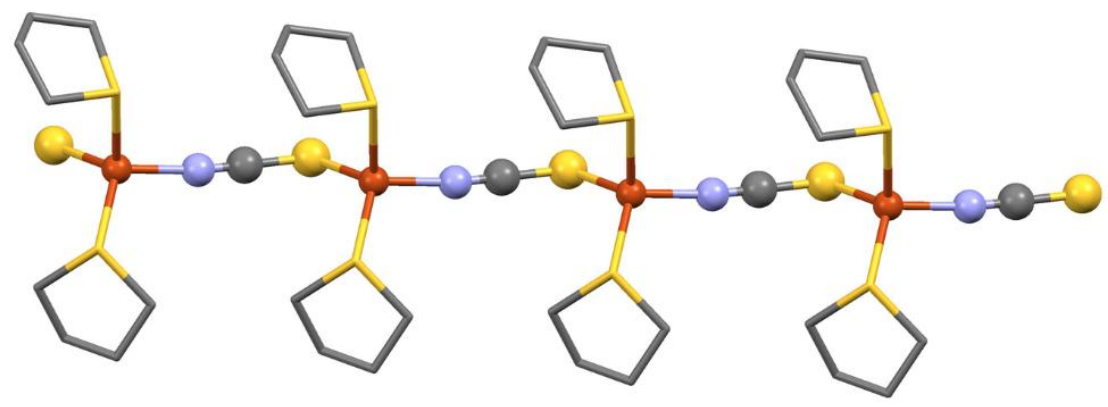


Figure 5: The chain structure of $\mathbf{4}$ viewed along $b$-axis. CuSCN atoms shown as ball and stick, and THT atoms as wireframe. Hydrogen atoms and disordered ligand positions are omitted. Selected bond lengths $(\AA)$ and angles $\left(^{\circ}\right): \mathrm{Cu}-\mathrm{SCN}=2.3438(15), \mathrm{Cu}-\mathrm{NCS}=1.967(5), \mathrm{Cu}-\mathrm{SR}_{2}=2.187(19), 2.400(17), \mathrm{Cu}-\mathrm{S}-\mathrm{C}$ $=105.07(18), \mathrm{C}-\mathrm{N}-\mathrm{Cu}=173.4(4)$.

\section{Conclusions}

We have reported the first alkyl monosulfide complexes of copper(I) thiocyanate. Five compounds were prepared by the reaction of $\mathrm{CuSCN}$ in neat $\mathrm{Me}_{2} \mathrm{~S}, \mathrm{Et}_{2} \mathrm{~S}, \operatorname{Pr}_{2}^{i} \mathrm{~S}$, and tetrahydrothiophene (THT). In the former case $\left\{\left[\mathrm{Cu}(\mathrm{SCN})\left(\mathrm{Me}_{2} \mathrm{~S}\right)_{2}\right]\right\}_{\mathrm{n}}$ (1a) forms upon cooling a solution of $\mathrm{CuSCN}$ in $\mathrm{Me}_{2} \mathrm{~S}$, while $\left\{\left[(\mathrm{CuSCN})\left(\mathrm{Me}_{2} \mathrm{~S}\right)\right]\right\}_{\mathrm{n}}$ (1b) is formed by rapid precipitation from the solution. Only $\left\{\left[\mathrm{Cu}(\mathrm{SCN})\left(\mathrm{Et}_{2} \mathrm{~S}\right)\right]\right\}_{n}$ (2) can be realized from a solution of $\mathrm{CuSCN}$ in $\mathrm{Et}_{2} \mathrm{~S}$. Sulfide compounds $\left\{\left[\mathrm{Cu}(\mathrm{SCN})\left(\operatorname{Pr}_{2}^{i} \mathrm{~S}\right)\right]\right\}_{\mathrm{n}}(3)$ and $\left\{\left[\mathrm{Cu}(\mathrm{SCN})(\mathrm{THT})_{2}\right]\right\}_{\mathrm{n}}$ (4) are formed from suspensions of $\mathrm{CuSCN}$ in the ligand. All compounds are thermally unstable, losing alkyl sulfide ligand over a course of hours at room temperature. None of the complexes show bridging through the sulfide ligand. Compounds $\mathbf{1 a}$ and $\mathbf{4}$ consist of zigzag CuSCN chains decorated with pairs of monodentate sulfide ligands. Compounds $\mathbf{2}$ and $\mathbf{3}$ consist of ladders of alternating and edge sharing $\mathrm{Cu}_{2} \mathrm{~S}_{2}$ and $(\mathrm{CuSCN})_{2}$ rungs. In both cases a monodentate sulfide ligand fills out tetrahedral copper coordination sphere. The sulfide compounds of CuSCN appear to be far less stable than those of the copper(I) halides and cyanide. This instability of $\mathrm{CuSCN}-\mathrm{SR}_{2}$ appears to be connected with the failure to promote network formation.

Acknowledgement. We are indebted to NSF (CHE-0443345) and the College of William and Mary for the purchase of the X-ray equipment.

Appendix A. Supplementary data: CCDC 1460762-1460765 contains the supplementary crystallographic data for $\mathbf{1 a}$ and $\mathbf{2 - 4}$. These data can be obtained free of charge via http://www.ccdc.cam.ac.uk/conts/retrieving.html, or from the Cambridge Crystallographic Data Centre, 12 Union Road, Cambridge CB2 1EZ, UK; fax: (+44) 1223-336-033; or e-mail: deposit@ccdc.cam.ac.uk. 
Supplementary data associated with this article can be found, in the online version.

References:

[1]: (a) H. O. House, C.-Y. Chu, J. M. Wilkins, J. J. Umen, J. Org. Chem. 40 (1975) 1460. (b) B. H. Lipshutz, S. Whitney, J. A. Kozlowski, C. M. Breneman, Tetrahedron Lett. 27 (1986) 4273. (c) S. H. Bertz, C. P. Gibson, G. Dabbagh, Organometallics 7 (1988) 227.

[2] (a) B. Lenders, D. M. Grove, W. J. J. Smeets, P. van der Sluis, A. L. Spek, G. van Koten. Organometallics 10 (1991) 786. (b) H. Maelger, F. Olbrich, J. Kopf, D. Abein E. Weiss. Z. Naturforsch. 47b (1992) 1276. (c) J. Zhou, G.-Q. Bian, J. Dai, Y. Zhang, Q.-Y. Zhu, W. Lu. Inorg. Chem. 45 (2006) 8486. (d) M. Heller W. S. Sheldrick. Z. Anorg. Allg. Chem. 630 (2004) 1869. (e) M. D. Dembo, L. E. Dunaway, J. S. Jones, E. A. Lepekhina, S. M. McCullough, J. L. Ming, X. Li, F. Baril-Robert, H. H. Patterson, C. A. Bayse, R. D. Pike. Inorg. Chim. Acta 364 (2010) 102. (f) K. M. Henline, C. Wang, R. D. Pike, J. C. Ahern, B. Sousa, H. H. Patterson, A. T. Kerr, C. L. Cahill. Cryst. Growth Des. 14 (2014) 1449. (g) P. D. Harvey, M. Knorr. J. Clust. Sci. 26 (2015) 411. (h) M. Knorr, A. Bonnot, A. Lapprand, A. Khatyr, C. Strohmann, M. M. Kubicki, Y. Rousselin, P. D. Harvey. Inorg. Chem. 54 (2015) 4076. (i) A. Bonnot, M. Knorr, F. Guyon, M. M. Kubicki, Y. Rousselin, C. Strohmann, D. Fortin, P. D. Harvey. Cryst. Growth Des. 16 (2016) 774.

[3] (a) D. Li, T. Wu, X.-P. Zhou, R. Zhou, X.-C. Huang. Angew. Chem., Int. Ed. 44 (2005) 4175. (b) J. Wang, Y.-H. Zhang, H.-X. Li, Z.-J. Lin, M.-L. Tong Cryst. Growth Des. 7 (2007) 2352. (c) Z.-M. Hao, J. Wang, X.-M. Zhang. CrystEngComm, 12 (2010) 1103.

[4] (a) F. B. Stocker, M. A. Troester, D. Britton. Inorg. Chem. 35 (1996) 3145. (b) F. B. Stocker, M. A. Troester. Inorg. Chem. 35 (1996) 3154. (c) F. Grifasi, M. R. Chierotti, C. Garino, R. Gobetto, E. Priola, E. Diana, F. Turci. Cryst. Growth Des. 15 (2015) 2929. 
[5] (a) O. N. Kataeva, D. B. Krivolapov, A. T. Gubaidullin, I. A. Litvinov, L. I. Kursheva, S. A. Katsyuba. J. Molec. Struct. 554 (2000) 127. (b) P. W. R. Corfield. Acta Crystallogr., Sect. E 70 (2014) 281.

[6] Preceding paper in this issue.

[7] T. Röttgers, W. S. Sheldrick. Z. Anorg. Allg. Chem. 627 (2001) 1976.

[8] G. A. Bowmaker, J. V. Hanna. Z. Naturforsch. B, 64 (2009) 1478.

[9] P. M. Graham, R. D. Pike. Inorg. Chem. 39 (2000) 5121.

[10] SAINT PLUS: Bruker Analytical X-ray Systems: Madison, WI, 2001.

[11] SADABS: Bruker Analytical X-ray Systems: Madison, WI, 2001.

[12] G. M. Sheldrick, Acta Crystallogr., Sect. A. 64 (2008) 112.

[13] C. B. Hubschle, G. M. Sheldrick, B. Dittick. J. Appl. Cryst. 44 (2011) 1281.

[14] SMART Apex II, Data Collection Software, version 2.1; Bruker AXS Inc.: Madison, WI, 2005.

[15] DIFFRAC.EVA, version 3.1; Bruker AXS Inc.: Madison, WI, 2013.

[16] (a) Q. Wang, G. Guo, T. C. W. Mak. Chem. Commun. (1999) 1849. (b) Z. Hao, X. Zhang. Cryst. Growth Des. 7 (2007) 64. (c) R. J. Trovitch, R. S. Rarig, J. A. Zubieta, R. L. LaDuca, Acta Crystallogr., Sect. E. 63 (2007) m339. (d) C. Näther, M. Wriedt. Dalton Trans. 46 (2009) 10125. (e) R. Peng, D. Li, T. Wu, X. Zhou, S. W. Ng. Inorg. Chem. 45 (2006) 4035. (f) S. Liang, M. Li, M. Shao, X. He. J. Mol. Struct. 875 (2008) 17. (g) W. R. Knapp, J. G. Thomas, D. P. Martin, M. A. Braverman, R. J. Trovitch, R. L. LaDuca. Z. Anorg. Allg. Chem. 875 (2007) 575. 
Table 1. Crystal and Structure Refinement Data.

\begin{tabular}{|c|c|c|c|c|}
\hline complex & 1a & 2 & 3 & 4 \\
\hline CCDC deposit no. & 1460762 & 1460764 & 1460765 & 1460763 \\
\hline color and habit & colorless block & colorless prism & colorless prism & colorless plate \\
\hline size, $\mathrm{mm}$ & $0.49 \times 0.42 \times 0.26$ & $0.45 \times 0.14 \times 0.11$ & $0.63 \times 0.10 \times 0.08$ & $0.38 \times 0.21 \times 0.06$ \\
\hline formula & $\mathrm{C}_{5} \mathrm{H}_{12} \mathrm{CuNS}_{3}$ & $\mathrm{C}_{5} \mathrm{H}_{10} \mathrm{CuNS}_{2}$ & $\mathrm{C}_{7} \mathrm{H}_{14} \mathrm{CuNS}_{2}$ & $\mathrm{C}_{9} \mathrm{H}_{16} \mathrm{CuNS}_{3}$ \\
\hline formula weight & 245.88 & 211.80 & 239.85 & 297.95 \\
\hline space group & $P 2_{1} / c(\# 14)$ & $P 2_{1} / n(\# 14)$ & $P 2_{1} / n(\# 14)$ & $P 2_{1}(\# 4)$ \\
\hline$a, \AA$ & $7.39230(10)$ & $5.82340(10)$ & $5.92320(10)$ & $5.8965(2)$ \\
\hline$b, \AA$ & $13.0297(3)$ & $9.6077(2)$ & $10.9226(2)$ & $9.3775(3)$ \\
\hline$c, \AA$ & $11.2206(2)$ & $16.2675(4)$ & $15.9989(3)$ & $11.7823(3)$ \\
\hline$\beta, \operatorname{deg}$ & $108.7360(10)$ & $96.4230(10)$ & $91.4730(10)$ & $98.004(2)$ \\
\hline volume, $\AA^{3}$ & $1023.49(3)$ & $904.45(3)$ & $1034.73(3)$ & $645.15(3)$ \\
\hline $\mathrm{Z}$ & 4 & 4 & 4 & 2 \\
\hline$\rho_{\text {calc }}, \mathrm{g} \mathrm{cm}^{-3}$ & 1.596 & 1.555 & 1.540 & 1.534 \\
\hline $\mathrm{F}_{000}$ & 504 & 432 & 496 & 308 \\
\hline$\mu(\mathrm{Cu} \mathrm{K} \alpha), \mathrm{mm}^{-1}$ & 8.211 & 7.093 & 6.271 & 6.626 \\
\hline temperature, $\mathrm{K}$ & $100(2)$ & $296(2)$ & $100(2)$ & $296(2)$ \\
\hline residuals: ${ }^{\mathrm{a}} \mathrm{R} ; \mathrm{R}_{\mathrm{w}}$ & $0.0232 ; 0.0581$ & $0.0327 ; 0.0936$ & $0.0228 ; 0.0589$ & $0.0294 ; 0.0737$ \\
\hline goodness of fit & 1.209 & 1.038 & 0.997 & 1.103 \\
\hline Flack & - & - & - & $0.03(4)$ \\
\hline
\end{tabular}




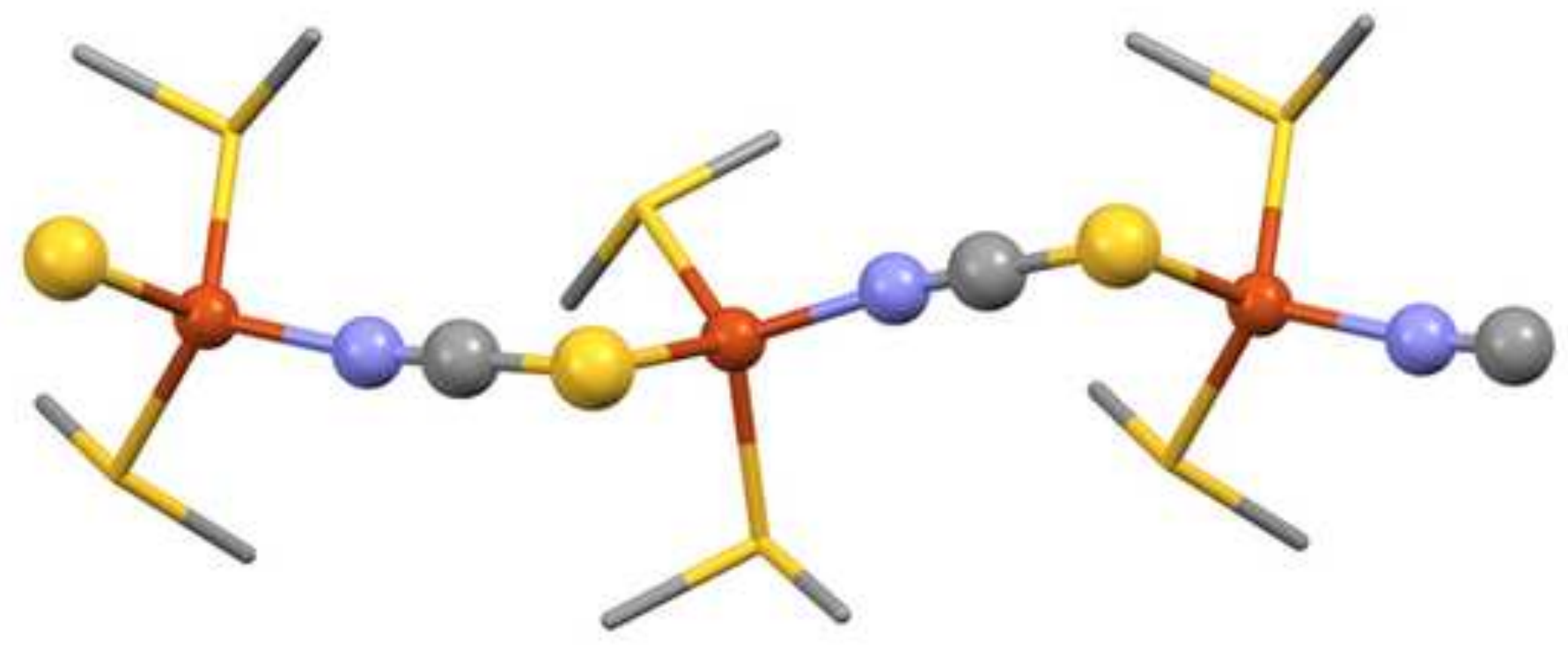

\section{$\mathrm{CuSCN}\left(\mathrm{Me}_{2} \mathrm{~S}\right)_{2}$}

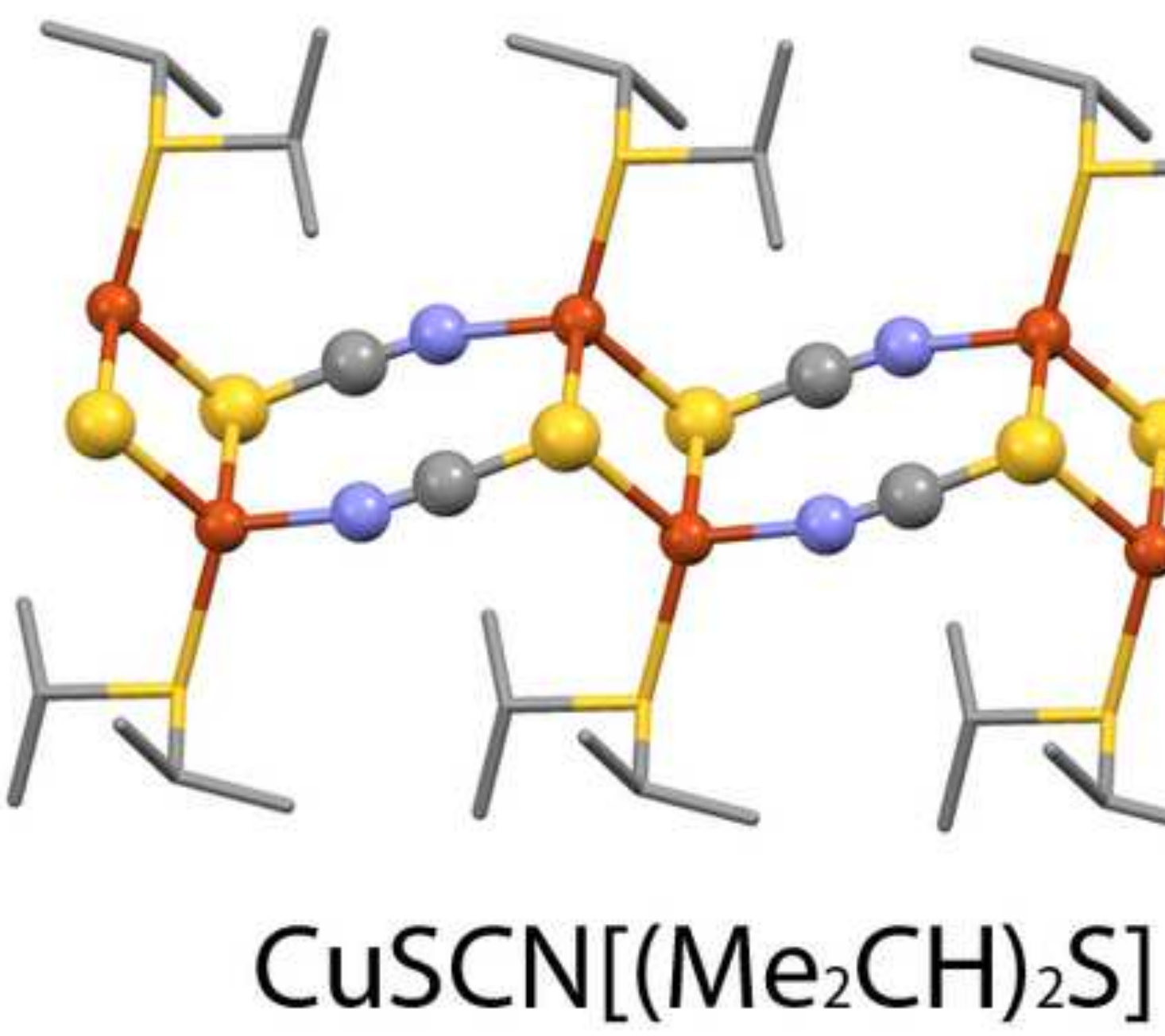




\section{Copper(I) Thiocyanate Networks with Aliphatic Sulfide Ligands.}

Gerardo Ayala and Robert D. Pike*

Synopsis:

Copper(I) thiocyanate forms complexes $\left\{\left[\mathrm{Cu}(\mathrm{SCN})\left(\mathrm{Me}_{2} \mathrm{~S}\right)_{2}\right]\right\}_{\mathrm{n}},\left\{\left[\mathrm{Cu}(\mathrm{SCN})\left(\mathrm{Me}_{2} \mathrm{~S}\right)\right]\right\}_{\mathrm{n}}$, $\left.\left\{[\mathrm{CuSCN})\left(\mathrm{Et}_{2} \mathrm{~S}\right)\right]\right\}_{\mathrm{n}}, \quad\left\{\left[(\mathrm{CuSCN})\left(\operatorname{Pr}_{2}^{i} \mathrm{~S}\right)\right]\right\}_{\mathrm{n}}, \quad$ and $\quad\left\{\left[(\mathrm{CuSCN})(\mathrm{THT})_{2}\right]\right\}_{\mathrm{n}} \quad(\mathrm{THT}=$ tetrahydrothiophene). In the $\mathrm{Me}_{2} \mathrm{~S}$ and THT complexes the zigzag chains are formed. In the $\mathrm{Et}_{2} \mathrm{~S}$ and $\operatorname{Pr}_{2}^{i} \mathrm{~S}$ complexes ladders are formed. Alkyl sulfide ligands are monodentate in all cases.

Drawing:
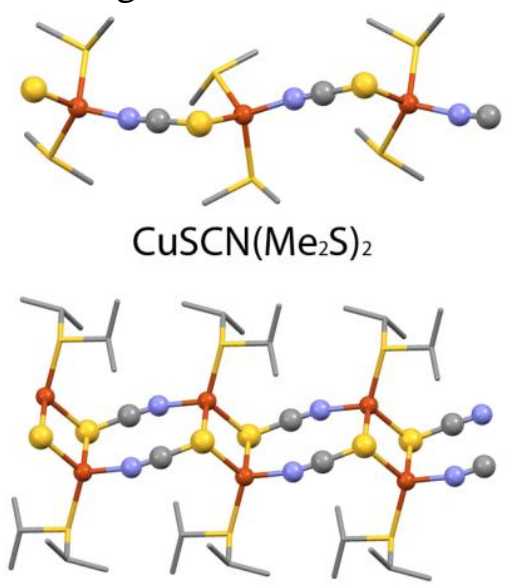

CuSCN $\left[\left(\mathrm{Me}_{2} \mathrm{CH}\right)_{2} \mathrm{~S}\right]$ 